\section{$\underset{\substack{\text { hommes } \\ \text { \& migrations }}}{ }$}

\section{Hommes \& migrations}

Revue française de référence sur les dynamiques

migratoires

1302 | 2013

Le Japon, pays d'immigration?

\title{
Free Angela and All Political Prisoners
}

Documentaire américain de Shola Lynch

\section{Anaïs Vincent}

\section{Q OpenEdition \\ 1 Journals}

\section{Édition électronique}

URL : http://journals.openedition.org/hommesmigrations/2517

DOI : 10.4000/hommesmigrations. 2517

ISSN : 2262-3353

\section{Éditeur}

Musée national de l'histoire de l'immigration

\section{Édition imprimée}

Date de publication : 1 avril 2013

Pagination : 185-187

ISBN : 978-2-919040-22-3

ISSN : $1142-852 X$

\section{Référence électronique}

Anaïs Vincent, «Free Angela and All Political Prisoners », Hommes \& migrations [En ligne], 1302 | 2013, mis en ligne le 16 septembre 2013, consulté le 22 septembre 2020. URL : http://

journals.openedition.org/hommesmigrations/2517; DOI : https://doi.org/10.4000/ hommesmigrations.2517

Ce document a été généré automatiquement le 22 septembre 2020.

Tous droits réservés 


\title{
Free Angela and All Political Prisoners
}

\author{
Documentaire américain de Shola Lynch
}

Anaïs Vincent

1 Free Angela est le deuxième documentaire de la réalisatrice et productrice américaine Shola Lynch. Comme dans son précédent film sur la députée Shirley Chisholm, elle se confronte à la biographie d'une icône afro-américaine. À travers le récit de ce destin personnel, elle met en lumière la force de l'engagement et du combat contre la discrimination raciale de la militante féministe communiste afro-américaine Angela Davis.

2 La jeune Angela décide très tôt de lutter contre l'injustice qui frappe sa communauté. Elle étudie la philosophie en France puis en Allemagne. Elle se familiarise avec les thèses de Marx et adhère rapidement au communisme. La libération du peuple noir doit se faire, selon elle, avec les outils du socialisme. Depuis l'Europe, elle entend la contestation des défenseurs des droits civiques prendre de l'ampleur dans son pays. Pour être au cœur des revendications, elle décide de rentrer. Elle milite au sein des Black Panthers, puis rejoint le Che-Lumumba Club, mais s'indigne contre la misogynie présente dans ces mouvements. Pour elle, le combat pour le respect des droits de la minorité noire n'a aucune chance d'être victorieux si les femmes restent asservies. Devenue professeur de philosophie à l'université de Californie, elle est radiée quelque temps plus tard pour ses opinions politiques. Elle se mobilise à corps perdu pour la libération de George Jackson, Fleeta Drumgo et John Clutchette, les "Frères de Soledad". Tout bascule quand elle est accusée d'avoir fomenté leur évasion qui coûte la vie à un juge. Dans les années 1970, J. Edgar Hoover, directeur du FBI, souhaite museler les leaders de ces mouvements protestataires. Des méthodes très contestables sont alors utilisées. Le Cointelpro (Counter Intelligence Program), un programme de contreespionnage, infiltre ces organisations et met en place des procès à charge pour discréditer leurs militants.

3 Dans ce climat de terreur, pour Angela Davis, la seule alternative est la cavale. Elle est finalement arrêtée et emprisonnée pendant vingt-deux mois. Jugée lors d'un long 
procès, elle sera acquittée grâce à la mobilisation internationale. Ce combat est raconté sans voix off, avec des extraits de films d'archives et des interviews. La parole des protagonistes jalonne ce récit. Ils reviennent tour à tour sur la xénophobie latente des instances politiques des années 1970, sur les injustices dont sont victimes les AfroAméricains et expliquent de quelle manière l'action de chacun a été déterminante. Mais avant d'être le témoignage d'une lutte historique, ce film montre comment la mobilisation peut permettre de gagner un combat. La réalisatrice insuffle un vent d'espoir dans le marasme de notre génération désenchantée. Alors que les mouvements d'extrême droite reprennent de l'ampleur, que le capitalisme laisse chaque jour derrière lui des millions de désœuvrés, l'histoire d'Angela Davis nous rappelle notre devoir de citoyen de lutter contre toute forme d'injustice et souligne le pouvoir de la contestation de masse.

Aujourd'hui, même si des travaux d'historiens et certaines révélations ont permis de mettre en lumière les abus de la politique de J. Edgar Hoover, certaines zones d'ombre demeurent encore au tableau.

Le 18 mai 2013, le nom d'Assata Shakur, la tante du célèbre rappeur Tupac Amaru Shakur (2Pac), une militante des droits civiques, ancienne membre des Black Panthers, figure désormais sur la liste des terroristes les plus recherchés aux États-Unis pour des faits remontants à 1971. Cette présumée ennemie du Pentagone est accusée d'avoir tué un policier dans une fusillade dans laquelle elle fut elle-même blessée. Elle est à l'époque condamnée à la prison à vie. Mais aucune preuve ne permet de proclamer sa culpabilité. En 1979, avec l'aide de son frère, elle s'évade. Elle se réfugie en 1984 à Cuba où elle réside actuellement. Comparer cette exilée à des djihadistes forcenés semble absurde. Cette militante n'a pas bénéficié de la même médiatisation qu'Angela Davis ni de la même mobilisation autour de sa cause. Comme le souligne l'héroïne du film de Shola Lynch, aujourd'hui il faut remettre de la patience au cœur de la politique. On ne peut pas se mobiliser une journée et puis plus rien. Les grands combats nécessitent du temps et de l'obstination. Free Angela and All Political Prisoners est une belle leçon de pugnacité, tant pour le choix de son sujet que pour sa réalisation. Il a fallu pas moins de huit ans pour que ce biopic puisse voir le jour. 